\title{
Genome-wide DNA methylation profile identified a unique set of differentially methylated immune genes in oral squamous cell carcinoma patients in India
}

Baidehi Basu $^{1 \dagger}$, Joyeeta Chakraborty ${ }^{1 \dagger}$, Aditi Chandra $^{1 \dagger}$, Atul Katarkar $^{1,2}$, Jadav Ritesh Kumar Baldevbhai ${ }^{3}$, Debjit Dhar Chowdhury ${ }^{3}$, Jay Gopal Ray ${ }^{3}$, Keya Chaudhuri ${ }^{2}$ and Raghunath Chatterjee ${ }^{1 *}$

\begin{abstract}
Background: Oral squamous cell carcinoma (OSCC) is one of the common malignancies in Southeast Asia. Epigenetic changes, mainly the altered DNA methylation, have been implicated in many cancers. Considering the varied environmental and genotoxic exposures among the Indian population, we conducted a genome-wide DNA methylation study on paired tumor and adjacent normal tissues of ten well-differentiated OSCC patients and validated in an additional 53 well-differentiated OSCC and adjacent normal samples.

Results: Genome-wide DNA methylation analysis identified several novel differentially methylated regions associated with OSCC. Hypermethylation is primarily enriched in the CpG-rich regions, while hypomethylation is mainly in the open sea. Distinct epigenetic drifts for hypo- and hypermethylation across CpG islands suggested independent mechanisms of hypo- and hypermethylation in OSCC development. Aberrant DNA methylation in the promoter regions are concomitant with gene expression. Hypomethylation of immune genes reflect the lymphocyte infiltration into the tumor microenvironment. Comparison of methylome data with 312 TCGA HNSCC samples identified a unique set of hypomethylated promoters among the OSCC patients in India. Pathway analysis of unique hypomethylated promoters indicated that the OSCC patients in India induce an anti-tumor T cell response, with mobilization of T lymphocytes in the neoplastic environment. Survival analysis of these epigenetically regulated immune genes suggested their prominent role in OSCC progression.
\end{abstract}

Conclusions: Our study identified a unique set of hypomethylated regions, enriched in the promoters of immune response genes, and indicated the presence of a strong immune component in the tumor microenvironment. These methylation changes may serve as potential molecular markers to define risk and to monitor the prognosis of OSCC patients in India.

Keywords: Oral squamous cell carcinoma, CTLA4, CpG island, Differentially methylated regions, Methylation-specific $\mathrm{PCR}$, Bisulfite cloning and sequencing, Gene expression

\footnotetext{
* Correspondence: rchatterjee@isical.ac.in

${ }^{\dagger}$ Equal contributors

'Human Genetics Unit, Indian Statistical Institute, 203 B. T. Road, Kolkata

700108, India

Full list of author information is available at the end of the article
} 


\section{Background}

Oral cancer consists of any malignant neoplasm in the lip, floor of the mouth, buccal mucosa, gingiva, retromolar trigone, palate, or in the tongue and is the most common form of cancer in the head and neck squamous cell cancer (HNSCC) category. It is the 11th most common cancer worldwide with an estimated 300,400 new cases and 145,400 deaths occurred in 2012 worldwide [1]. Globally, India has the highest incidence of oral cancer per year and is the leading cancer among Indian men and fifth most common among women [2, 3]. Most oral malignancies occur as squamous cell carcinomas (SCCs), and many OSCCs develop from premalignant conditions of the oral cavity [4]. A wide array of conditions have been implicated in the development of oral cancer, including leukoplakia, erythroplakia, palatal lesion of reverse cigar smoking, oral lichen planus, oral submucous fibrosis, discoid lupus erythematosus, and hereditary disorders such as dyskeratosis congenital and epidermolysis bullosa [5]. Despite the general accessibility of the oral cavity during physical examination, many malignancies are not diagnosed until late stages of the disease. The major risk factors for oral cavity cancer are smoking, smokeless tobacco, alcohol, and HPV infection [1]. The higher incidence of oral cancer in India, Taiwan, and other neighboring countries is attributed to popularity of different oral habits like chewing smokeless tobacco, betel quid, and areca nut [1].

Oral cancer is a multifactorial disease involving genetic and epigenetic abnormalities. The addition of a methyl group at the cytosine residue of $\mathrm{CpG}$ dinucleotide have a profound effect on initiation and progression of cancer [6-9]. Hypermethylation of CpG islands (CGIs) in the promoter region results in transcriptional silencing of tumor suppressor genes, whereas hypomethylation leads to oncogene activation in many cancers [7-10]. As DNA methylation alteration often occurs early in cancer development, candidate methylation markers may be valuable for early and specific cancer detection [11-13]. Promoter hypermethylationmediated silencing of different classes of genes involved in cell-cycle regulation, signaling pathways, angiogenesis, proliferation, differentiation, DNA repair, and apoptosis are reported in OSCC [13-22].

Studies have indicated involvement of genetic, epigenetic, and oral habits in the development of oral cancer. The contribution of the varied risk factors in the Indian subcontinent may lead to a distinct disease pathogenesis. The mechanisms by which different habits influence phenotype and disease risk may involve the altered epigenetic regulation of genes. Recently, candidate genespecific studies identified epigenetic modifications in the promoter regions of OSCC patients in India. P16, DAPK, and MGMT gene promoter hypermethylation was reported in oral cancer tissues compared to corresponding adjacent normal mucosa [23]. EDNRB, KIF1A, DCC, P16, P15, hMLH1, MGMT, and E-cadherin gene promoter hypermethylation is also observed in Indian OSCC patients [24, 25]. Studies with esophageal cancer patients from North Eastern Indians have shown that tobacco consumption possibly interacts with carcinogenmetabolizing genes and modulate the promoter hypermethylations of tumor suppressor genes [26]. However, most of these studies focused on cancer-associated hypermethylation at specific genes. Surprisingly, OSCCassociated DNA hypomethylation received little attention. Furthermore, global hypomethylation observed in OSCC have not been characterized profoundly among Indian patients.

High throughput genome-wide methylation study provides a comprehensive platform to understand the overview of DNA methylation [27]. Genome-wide DNA methylation profiles in the OSCC patients of this region thus may help us to understand the disease pathogenesis. However, to date, there is no systematic genomewide study to investigate whether changes in DNA methylation can influence the OSCC development among the patients in India. In the present study, we have determined the global methylation status of welldifferentiated OSCC and adjacent normal tissues using Illumina Infinium 450K BeadChip Array. Differentially methylated regions were validated in another cohort of OSCC patients in India. Gene expression profiles of some of these aberrantly methylated genes showed inverse correlation with the promoter methylation. A comparative analysis of the methylome data of these OSCC patients with the available TCGA HNSC patients identified some novel genes, which showed exclusive differential methylation in OSCC patients of Indian population. Survivability analysis suggested prognostic significance of some of these genes in OSCC.

\section{Results}

Genome-wide DNA methylation distribution in the welldifferentiated OSCC

We have determined the genome-wide DNA methylation profiles of OSCC patients using the Illumina Infinium $450 \mathrm{~K}$ array. In total, 64 OSCC patients were recruited for the study (Table 1, Additional file 1: Table S1). All tissue samples were histopathologically verified and diagnosed to be well-differentiated OSCC. Ten pairs of cancer and adjacent normal tissues and one unpaired cancer tissue from the buccal mucosa of OSCC patients were used for the global methylome analysis. To avoid the influence of DNA methylation on $\mathrm{X}$ chromosome inactivation, we considered only the autosomal probes for further analysis. Probes showing $|\Delta \beta| \geq 0.20$ between the cancer and adjacent normal tissues with adjusted $P$ value $\leq 0.05$ were 
Table 1 Demographic and clinical characteristics of the discovery and validation set

\begin{tabular}{lll}
\hline Characteristics & \multicolumn{2}{l}{ Patient information } \\
\cline { 2 - 3 } & Discovery set & Validation set \\
\hline Total patients & 11 & 53 \\
Normal/disease & $10 / 11$ & $53 / 53$ \\
Age range (in years) & $40-90$ & $27-78$ \\
Mean age (SD) (in years) & $51.37(14.33)$ & $53.50(12.45)$ \\
No. of males/females & $7 / 4$ & $39 / 14$ \\
HPV: positive/negative & $6 / 5$ & $29 / 24$ \\
Oral habits & & \\
$\quad$ Smoking tobacco & 1 & 2 \\
Chewing tobacco & 2 & 22 \\
Other habits & 1 & 1 \\
Multiple habits & 4 & 10 \\
No habits & 2 & \\
\hline
\end{tabular}

defined as differentially methylated probes (DMPs). Following the criteria, we identified 21,810 DMPs including 16,140 hypomethylated and 5670 hypermethylated probes. Hierarchical clustering of top 2000 DMPs showed separate clustering of OSCC and adjacent normal tissues (Fig. 1a), except for two normal samples which clustered with disease group. This might be due to hyperplastic to mild dysplastic cells, as noticed in the histopathology of these samples (Additional file 2: Figure S1A-G). However, no distinct clustering was observed between HPV-positive and HPV-negative samples. Separate comparison between HPV-positive and HPV-negative samples could not identify any probe that was significantly differentially methylated according to our criterion $|\Delta \beta| \geq 0.20$ and adjusted $P$ value $\leq 0.05$.

Next, we sought to determine the enrichment of 21,810 DMPs at CpG islands (CGIs) and non-CGI regions of the genome (Additional file 2: Figure S2A, B). Enrichment of hyper- and hypomethylated probes were significantly different between the CGIs and non-CGI regions (Additional file 2: Figure S2A, B). Approximately, $85 \%$ of the DMPs were in the non-CGI, and majority $(82 \%)$ of these probes are hypomethylated. On the contrary, majority of the CGI-overlapped DMPs (70\%) are hypermethylated (Additional file 2: Figure S2A, B). Further classification of these DMPs based on their enrichment at CGIs, shores, shelves, and open sea clearly showed that majority of the hypermethylated probes (72\%, i.e., 4082 DMPs) were enriched in the CGIs, shores, and shelves, whereas hypomethylated probes $(67 \%)$ were mostly enriched in the open sea (Fig. 1b). To determine the genomic localization of these probes, we mapped these DMPs into the promoters, exons, introns, repeat regions, and other regions (Additional file 2:
Figure S2C, D). Complying with the previous observations, we found that the CGI-overlapped DMPs were mostly hypermethylated and the non-CGI DMPs were mostly hypomethylated irrespective of their genomic localizations. The pattern of differential methylation across the CGIs, shores, and shelves showed contrasting characteristics between hypomethylated and hypermethylated regions. The hypermethylation of the CpGs were specifically localized to the CGIs ( $P$ value $\leq 0.0001)$, while shores and shelves did not show any significant differential methylation $(P$ value $\geq 0.05)$. On the contrary, significant hypomethylation $(P$ value $\leq 0.05)$ was observed across CGIs, shores, and shelves between tumors and adjacent normal tissues, suggesting different mechanisms of hypo- and hypermethylation in OSCC development (Fig. 1c). The hierarchical clustering of average $\beta$ values for the promoter and the CGIs also indicated the distinct epigenetic regulations between the welldifferentiated OSCC and adjacent normal tissues (Additional file 2: Figure S3A, B).

\section{Validation of differentially methylated promoters}

In order to validate the $450 \mathrm{~K}$ array results, we determined the methylation status of five randomly selected differentially methylated promoters by sequencing the cloned bisulfite-converted DNA samples of OSCC and adjacent normal tissues (Fig. 2a, b, Additional file 2: Figure S4). Clonal validation showed hypermethylation for the HLA-DPB1 (12 to 81\%), LDLRAD4 (0 to 38\%), LHX1 (34 to $98 \%$ ), and $L X N$ (2 to $29 \%$ ) promoters and hypomethylation for PTPN22 (86 to 30\%) in tumors compared to adjacent normal tissues. These results were consistent with that of the $450 \mathrm{~K}$ array data. Furthermore, a panel of 14 differentially methylated promoters were selected for validation in additional 53 pairs of tumor and adjacent normal tissues using methylationspecific quantitative real-time PCR (qMSP) (Table 2). Most of the differentially methylated promoters showed 60 to $90 \%$ concordance with the results obtained from the genome-wide methylation data. Some of the discordant results can also be attributed to the hyperplastic or dysplastic tissue morphology on some of the adjacent normal samples.

\section{Transcriptional effects of aberrant DNA methylation}

To investigate the transcriptional regulation of differentially methylated promoters in OSCC compared to adjacent normal tissues, we studied gene expression profile of 14 differentially methylated genes identified from the discovery cohort (Fig. 2c, d, Additional file 2: Figure S5, 6). These included seven genes with hypermethylated promoters, namely, LXN, ZNF154, ZNF577, ZSCAN31, CTDSP1, LDLRAD4, and HLA-DPB1, and seven with hypomethylated promoters, including PTPN22, RUNX1, 


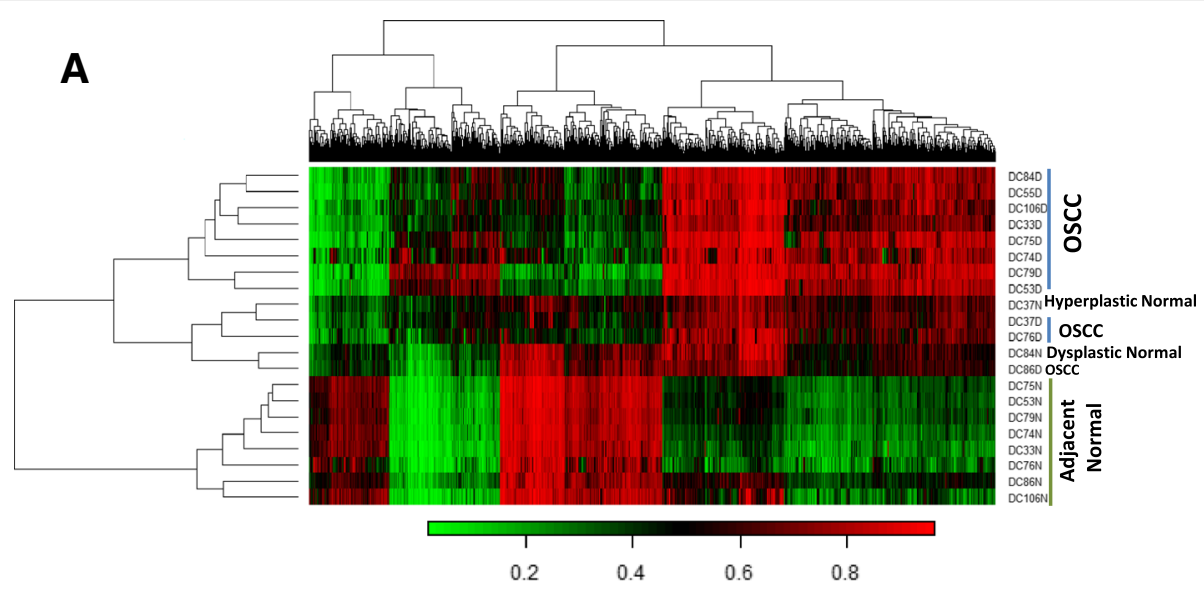

B
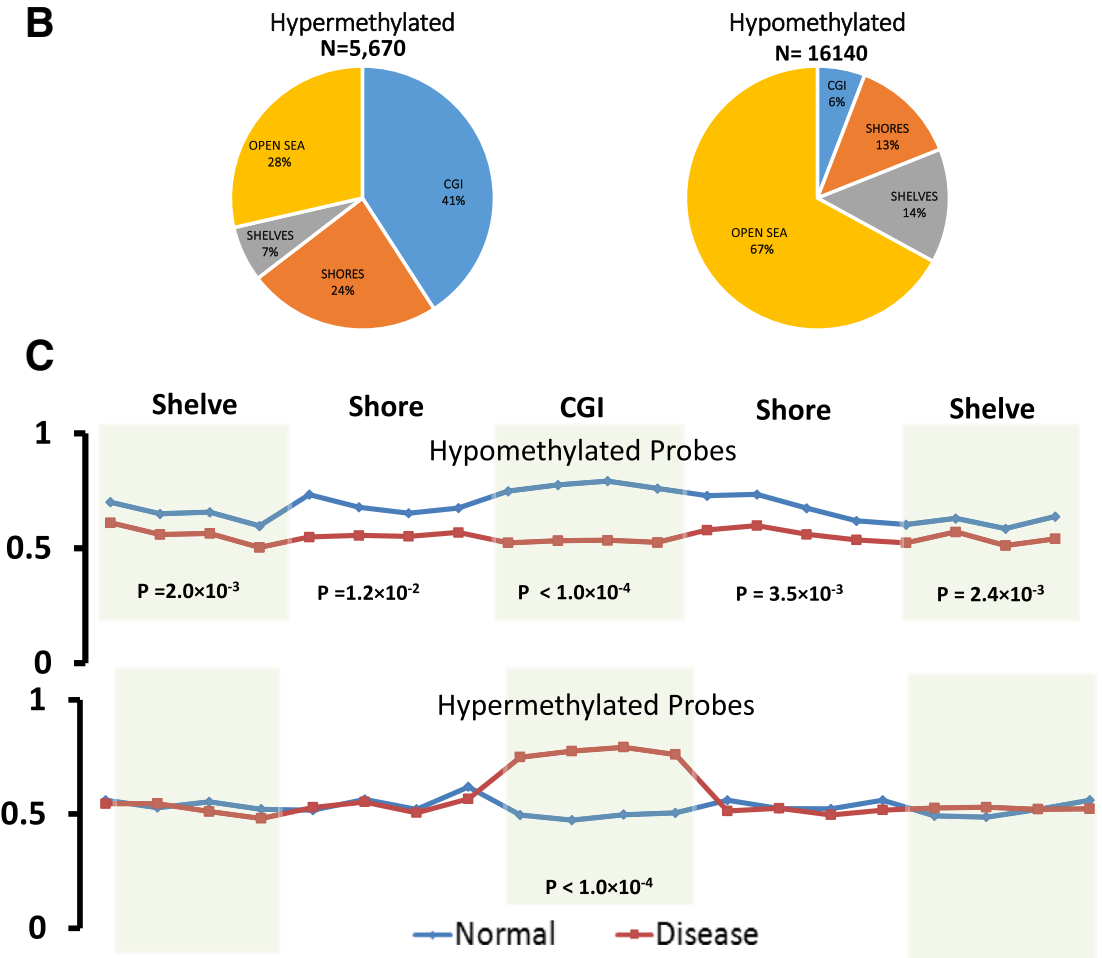

Fig. 1 Distribution of differentially methylated probes (DMPs). a Heatmap of top 2000 DMPs. Hierarchical clustering showing separate grouping of DMPs for OSCC and adjacent normal tissue. b Genomic localisation of hypermethylated and hypomethylated probes at the CpG islands (CGIs), shore, shelves, and open sea. c Average methylation across the CGls, shores, and shelves for hypo- and hypermethylated CGls

IL6, CD28, TLR1, CD80, CD22, and TNFa. Genes with hypermethylated promoters such as $L X N(P$ value $=2.94 \times$ $\left.10^{-2}\right), Z N F 154\left(P\right.$ value $\left.=3.10 \times 10^{-2}\right), C T D S P 1(P$ value $=$ $\left.2.40 \times 10^{-2}\right)$, and ZNF577 $\left(P\right.$ value $\left.=1.80 \times 10^{-3}\right)$ showed significant downregulation in OSCC tissues compared to the adjacent normal tissues (Fig. 2c, d, Additional file 2: Figure S5). ZSCAN31 and LDLRAD4 showed downregulation but did not reach the level of significance at 0.05. Only, $H L A-D P B 1$ showed significant upregulation $(P$ value $=$ $3.80 \times 10^{-2}$ ) in spite of its promoter getting hypermethylated. A closer look into the methylation data showed hypomethylation at the promoter region of another isoform of the HLA-DPB1 gene, which may be the reason for this discordant expression profile. Similarly, significant upregulations were observed for the hypomethylated genes PTPN22 $\left(P\right.$ value $\left.=5.9 \times 10^{-3}\right), R U N X 1 \quad(P$ value $=4.5 \times 10$ $\left.{ }^{-3}\right)$, IL6 $\left(P\right.$ value $\left.=1.56 \times 10^{-2}\right), C D 28\left(P\right.$ value $\left.=7.5 \times 10^{-3}\right)$, TLR1 $\left(P\right.$ value $\left.=2.63 \times 10^{-2}\right), C D 80\left(P\right.$ value $\left.=3.34 \times 10^{-5}\right)$, and TNFa $\left(P\right.$ value $\left.=9.8 \times 10^{-3}\right)($ Fig. $2 \mathrm{~d}$, Additional file 2 : Figure S6). The gene expression analysis was consistent with methylation status and further showed the influence of differential promoter methylation in regulating the 

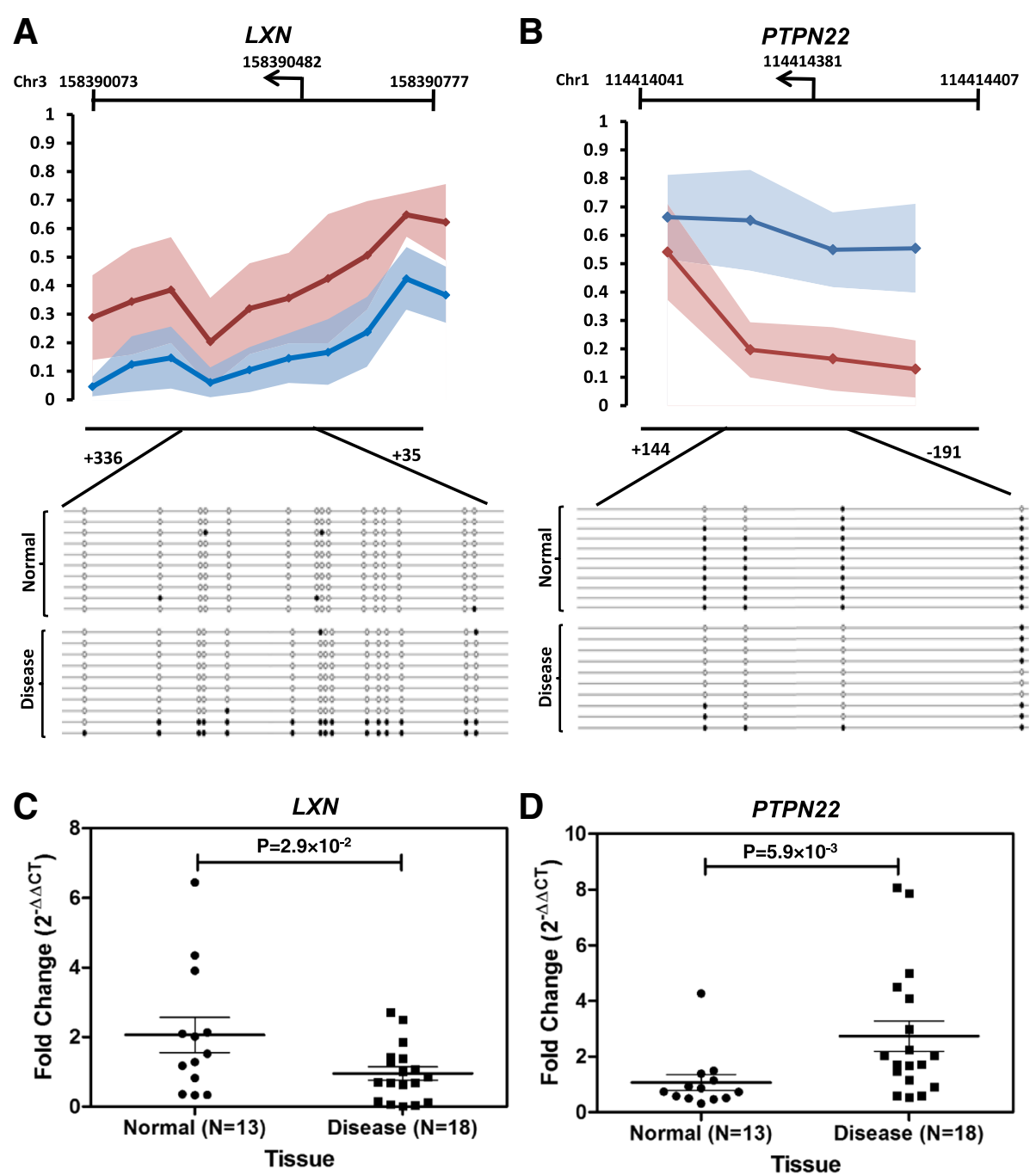

Fig. 2 Validation of HumanMethylation450K bead chip data. The upper panel shows the avergae $\beta$ values, and the lower panel shows the clonal validation by sequencing the bisulfite-converted products of $\mathbf{a}$ LXN and $\mathbf{b}$ PTPN22 promoters. The filled circle in the lower panel represents the methylated, and the open circle represents the unmethylated CpGs. Gene expression of $\mathbf{c}$ LXN and $\mathbf{d}$ PTPN22 showed significant differential expression between OSCC and adjacent normal tissues, correlating with methylation status

transcriptional activity of the genes. This also strengthened the validity of the differentially methylated genes identified in our discovery cohort.

\section{Comparison of methylation changes with TCGA data}

We compared the genome-wide DNA methylation data of the OSCC patients in India with that of the available TCGA HNSC samples (https://tcga-data.nci.nih.gov/ docs/publications/tcga/?). We only considered 312 samples at stages $1,2,3$, and $4 \mathrm{~A}$ among the 526 publicly available TCGA HNSC samples (Additional file 3: Table S2). As we do not have any patients with malignancies at the larynx, alveolar ridge, oropharynx, and hypopharynx and tonsil carcinoma, remaining 215 TCGA samples with malignancies at these regions were not included in our comparative analysis. Hazard ratio was estimated in
Cox model based on the death due to oral cancer by age, tumor stage, and node involvement. Significant risk was observed only for the age at the initial pathological diagnosis of OSCC patients, while tumor stages and node involvement status showed marginal increased risk but did not reach the level of significance at 0.05 (Additional file 3: Table S3). Approximately, $92.7 \%(14,975)$ of the hypomethylated and $100 \%$ of the hypermethylated probes had similar methylation pattern, at least with one stage of the TCGA samples. Interestingly, a subset of differentially methylated probes (1165) were uniquely hypomethylated in tumor tissues of OSCC patients in India. The methylation profile of these probes were significantly different (adjusted $P$ value $\leq 0.05$ ) from all stages of the TCGA data (Fig. 3a, Additional file 2: Figure S7-9). We determined the genomic distribution 
Table 2 Validation of differentially methylated regions

\begin{tabular}{|c|c|c|c|c|c|}
\hline Methylation status in 450K array & Overlap with CGI & Gene & No. of samples & No. of concordant samples & $\%$ of concordant samples \\
\hline \multirow[t]{7}{*}{ Hypermethylated } & \multirow[t]{4}{*}{ CGl } & ZNF577 & 53 & 42 & 79.25 \\
\hline & & HLA-DPB1 & 51 & 38 & 74.51 \\
\hline & & $L H X 1$ & 53 & 41 & 77.36 \\
\hline & & MYH14 & 13 & 11 & 84.62 \\
\hline & \multirow[t]{3}{*}{ Non-CGl } & ZSCAN31 & 47 & 35 & 74.47 \\
\hline & & LDLRAD4 & 53 & 37 & 69.81 \\
\hline & & $L X N$ & 53 & 37 & 69.81 \\
\hline \multirow[t]{7}{*}{ Hypomethylated } & \multirow[t]{2}{*}{ CGl } & PIWIL 1 & 14 & 13 & 92.86 \\
\hline & & MFAP2 & 11 & 9 & 81.82 \\
\hline & \multirow[t]{5}{*}{ Non-CGl } & PTPN22 & 53 & 33 & 62.26 \\
\hline & & SPNS3 & 14 & 10 & 71.43 \\
\hline & & AIM2 & 12 & 10 & 83.33 \\
\hline & & SLAMF1 & 12 & 8 & 66.67 \\
\hline & & SPATA13 & 10 & 7 & 70.00 \\
\hline
\end{tabular}

of the common and unique DMPs. We observed that the hypermethylated probes at the CGIs were mainly enriched at the promoters, while hypomethylated probes at the CGIs were primarily enriched at the exons and introns (Fig. 3b, Additional file 2: Figure S2B, C). On the contrary, both hypo- and hypermethyated probes at the non-CGIs are mostly enriched in the introns. Among the 1165 unique DMPs, 162 probes overlapped with promoter region of 134 genes. Among these, 40 promoters were overlapped with CGI, while 94 were non-CGIassociated promoters. (Additional file 4: Table S4).

\section{Gene ontology enrichment and IPA analysis of differentially methylated promoters}

To determine the functional implication of the common and unique DMPs, we performed gene ontology analysis. In total, 21 biological processes have been enriched at least by 1.5 -fold with enrichment $P$ value $\leq 0.01$ for the common hypermethylated promoters (Additional file 2: Figure S10). Majority of the enriched biological processes are related to regulation of transcription, embryonic morphogenesis, cell signaling, transmission of nerve impulse, and multicellular organismal response to stress. Among the common hypomethylated promoters, the major biological processes are mainly related to sensory perception like sensory perception of chemical stimulus and cognition, inflammatory response, Gprotein-coupled receptors, and metal ion transport. Twelve biological processes are significantly enriched for the unique hypomethylated promoters. These are immune response, positive regulation of cytokine biosynthesis, regulation of cell proliferation, $\mathrm{T}$ cell activation, and etc. Enrichment of these immune response genes indicates infiltration of immune cells into the tumor microenvironment. Our discovery cohort consists of both HPV-positive and HPV-negative OSCC samples. We did not find any differential methylation for these immune genes between OSCC and adjacent normal tissues, suggesting that the unique hypomethylation in these immune genes are not consequence of HPV infection. To determine the pathways that may be effected by the unique hypomethylated promoters, we performed ingenuity pathway analysis. The top significantly enriched canonical pathways are the IL9 signaling and CTLA4 signaling in cytotoxic T lymphocytes (Fig. 4). CTLA4 activation upon promoter hypomethylation indicates the negative regulation of effector $\mathrm{T}$ cell activation. Overlapping the common hypomethylated promoter with the CTLA4 signaling pathway suggested preferential binding of CD86 with CTLA4 than CD28 to negatively regulate the cytotoxic $\mathrm{T}$ cell activation in the neoplastic environment (Fig. 4b). CD28 promoter is hypomethylated in both TCGA and OSCC patients in India and found to be upregulated in the OSCC tissues compared in the adjacent normal tissues (Additional file 2: Figure S6D, S8B). We determined the gene expression profile of both CD86 and CTLA4 in the OSCC and adjacent normal tissues (Fig. 5). Both CD86 $\left(P\right.$ value $\left.=6.10 \times 10^{-3}\right)$ and CTLA4 $\left(P\right.$ value $\left.=1.30 \times 10^{-3}\right)$ showed significant overexpression in the OSCC tissues compared in the adjacent normal tissues, which further validated the epigenetic regulation of CD86 and CTLA4, specifically among the OSCC patients in India.

\section{Clinical significance of epigenetically regulated immune genes}

We next focused on the clinical significance of 134 unique differentially methylated genes observed in our 

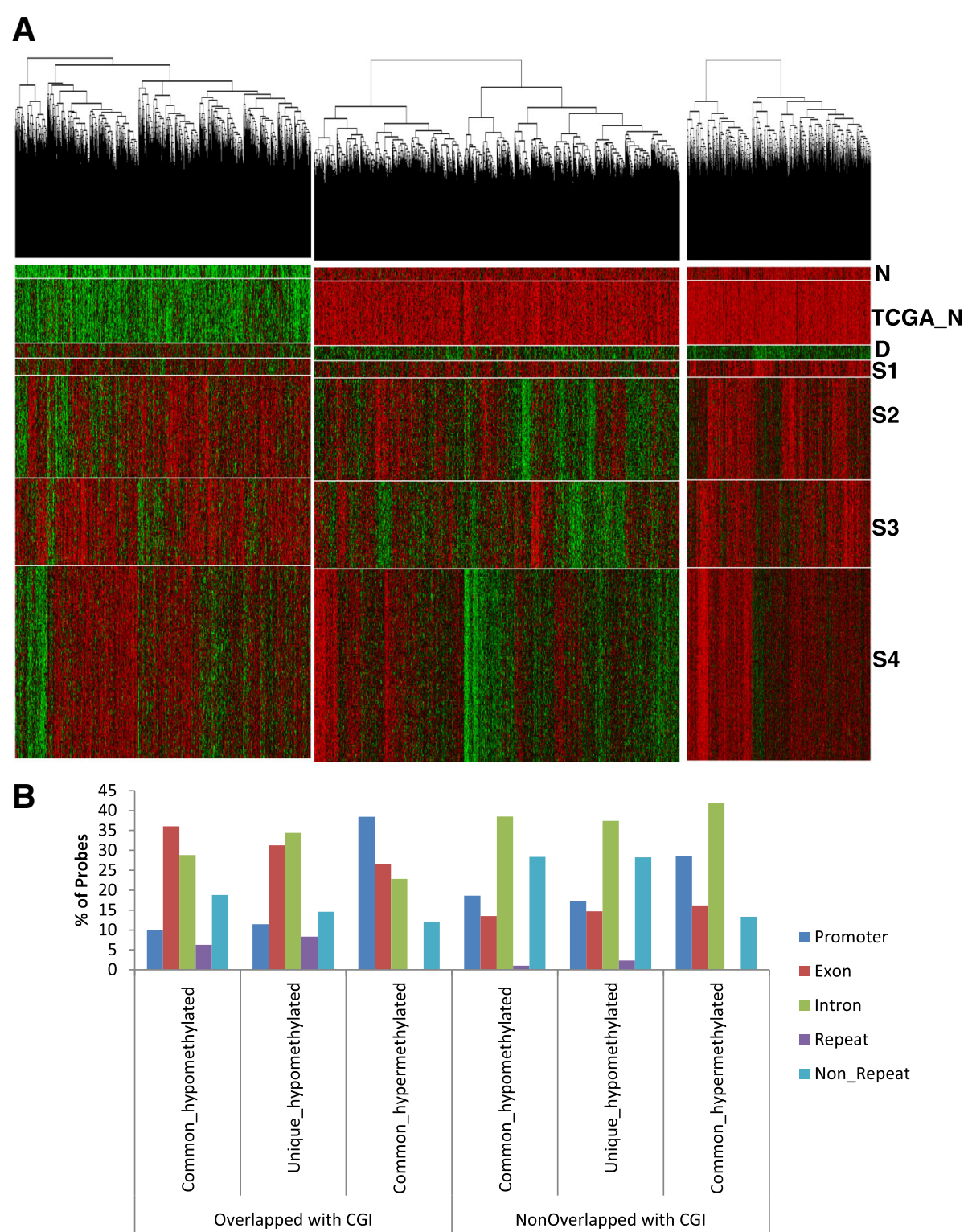

Fig. 3 Comparison of HumanMethylation450K bead chip with TCGA HNSC samples. a Hierarchical clustering of common hypermethylated, common hypomethylated, and unique hypomethylated probes in OSCC (D) and adjacent normal samples in India (N), and TCGA normal (TCGA_N) and HNSC samples for stages 1 (S1), 2 (S2), 3 (S3), and 4A (S4). b Genomic localization at the promoters, exons, introns, repeat regions, and other regions of common hypomethylated, hypermethylated, and unique hypomethylated probes that are overlapped with CGIs and non-CGls

study. The survival analysis based on the top 30 unique DMPs failed to show any significant association with clinical outcome of the TCGA HNSC patients. However, expression profile of 17 unique differentially methylated genes showed significant prognostic relevance in HNSC. Higher expression of CTLA4 ( $P$ value $\left.=4.06 \times 10^{-2}\right)$, CCR10 $\quad\left(P\right.$ value $\left.=8.94 \times 10^{-3}\right), \quad$ SLAMF1 $\quad(P$ value $=$ $\left.4.85 \times 10^{-3}\right), \quad$ SLC26A1 $\left(P\right.$ value $\left.=1.08 \times 10^{-2}\right)$, TNFRSF4 $\left(P\right.$ value $\left.=3.90 \times 10^{-4}\right), A P O B R\left(P\right.$ value $\left.=2.58 \times 10^{-2}\right)$, CACNA2D3 $\left(P\right.$ value $\left.=1.42 \times 10^{-3}\right), C L N K(P$ value $=$ $\left.4.77 \times 10^{-4}\right), \quad B F S P 2\left(P\right.$ value $\left.=8.79 \times 10^{-4}\right), \quad F C R L 6(P$ value $\left.=6.14 \times 10^{-3}\right), \quad$ MFSD7 $\quad\left(P \quad\right.$ value $\left.=3.52 \times 10^{-2}\right)$,
P2RY14 $\left(P\right.$ value $\left.=1.67 \times 10^{-4}\right)$, TLR9 $(P$ value $=8.75 \times 10$ $\left.{ }^{-3}\right)$, and $Z A P 70\left(P\right.$ value $\left.=1.28 \times 10^{-4}\right)$ was significantly correlated with better disease prognosis (Fig. 6, Additional file 2: Figure S11, 12). On the contrary, low expression of $C A M K 2 B \quad\left(P \quad\right.$ value $\left.=4.42 \times 10^{-2}\right)$, MTHFD1L $\left(P\right.$ value $\left.=2.27 \times 10^{-2}\right), T K T(P$ value $=3.96 \times$ $10^{-2}$ ) was significantly associated with better survival (Fig. 6, Additional file 2: Figure S12). Ten genes, out of these 14 genes that showed significantly better prognosis with higher expression, are involved in immune response pathways (Fig. 6, Additional file 2: Figure S11E, F). The Kaplan-Meier test based on the gene expression profile 


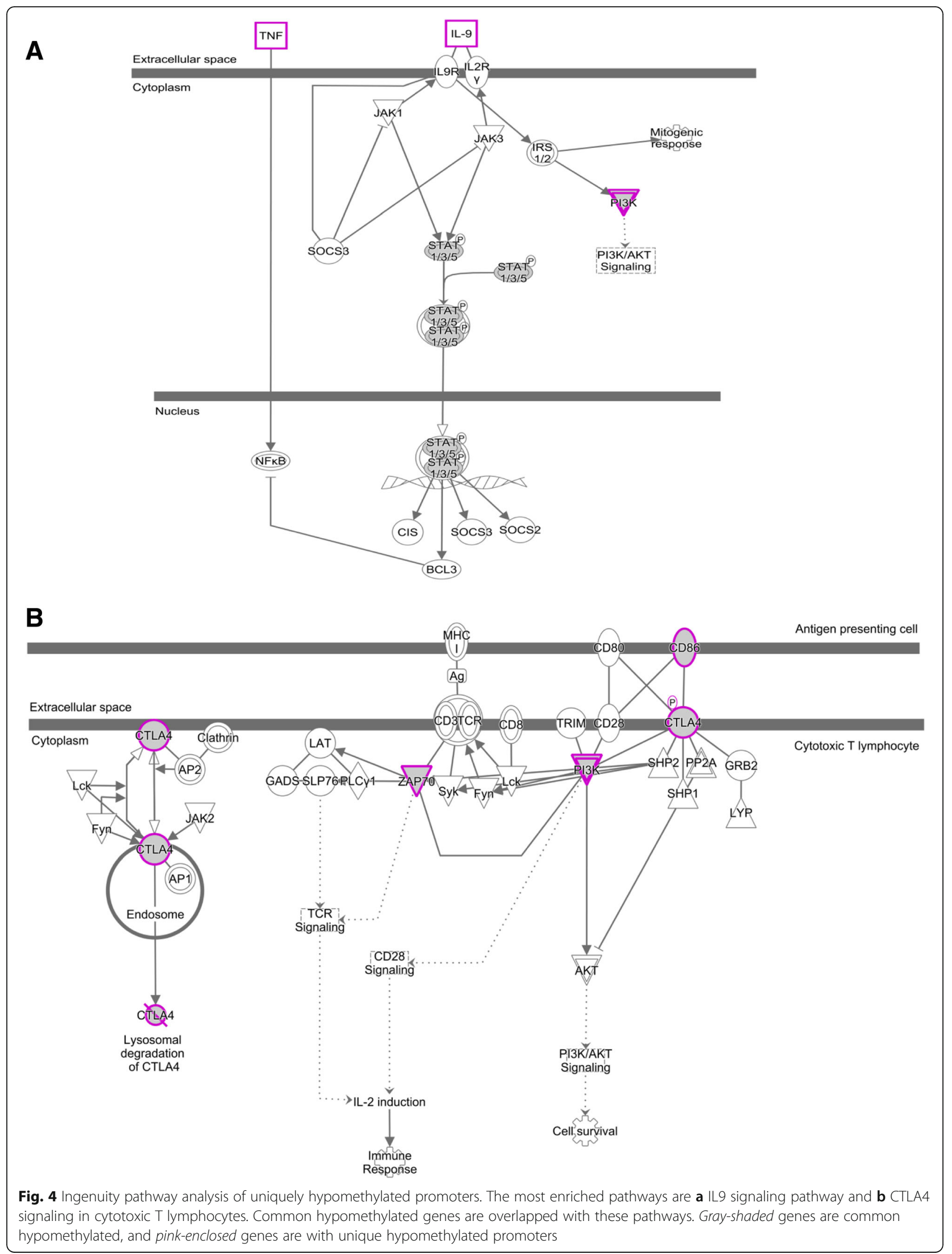



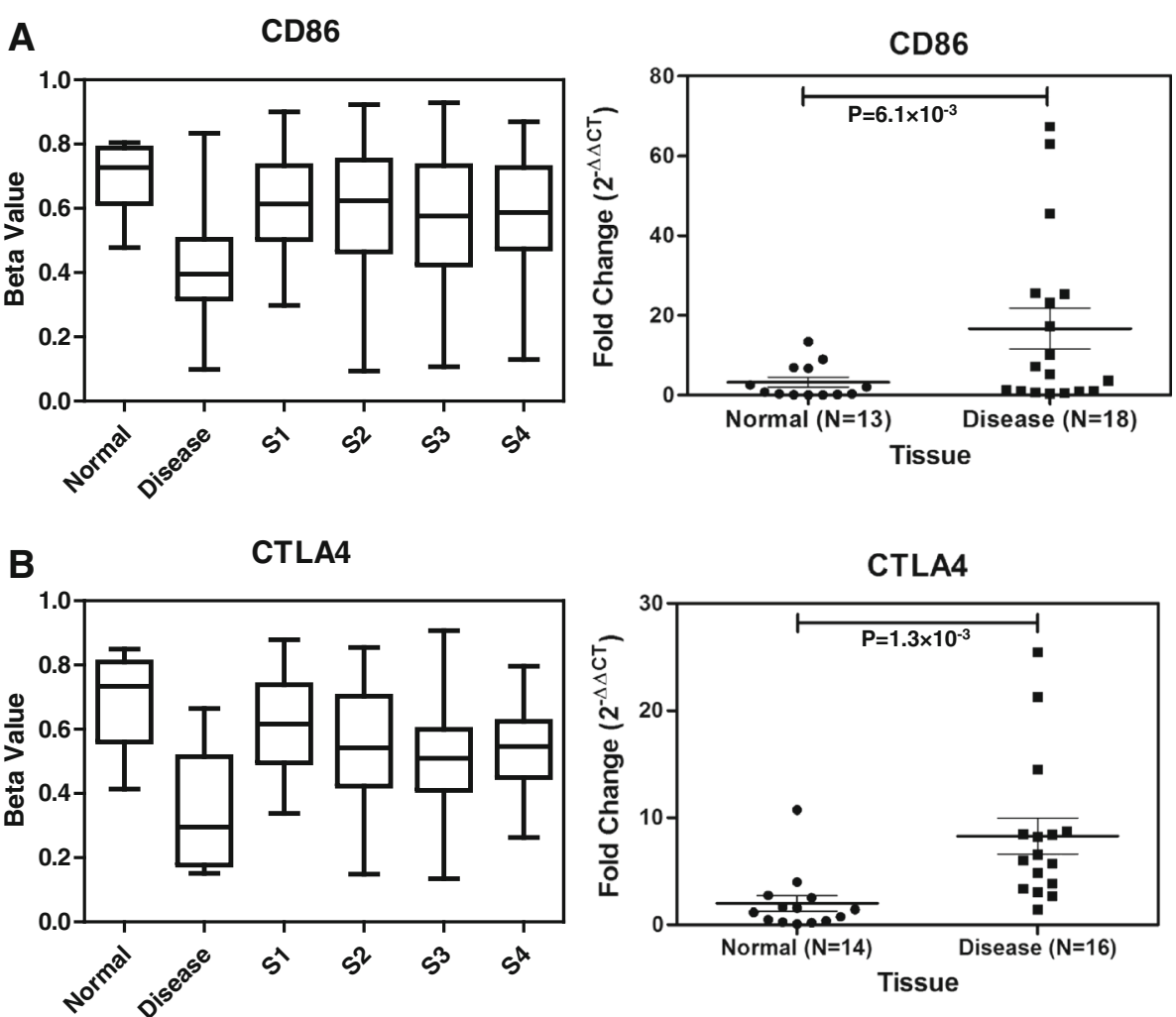

Fig. 5 Comparison of uniquely hypomethylated probe between human methylation 450K bead chip and TCGA samples. Methylation status of unique probes on $\mathbf{a}$ CD86 and $\mathbf{b}$ CTLA4 promoter in OSCC (disease) and adjacent normal samples (normal) in India and different stages of TCGA samples (S1, stage 1; S2, stage 2; S3, stage 3; and S4, stage 4A). Methylation profile of these genes in disease tissue of Indian patients was significantly different from their normal counterpart, as well as from disease stages S1, S2, S3, and S4A of TCGA samples. Gene expression (fold change) of CD86 and CTLA4 showed significantly higher expression in OSCC compared in the adjacent normal tissues among Indian samples. $P$ value $\leq 0.05$ was considered significant

of CTLA4 showed significantly $(P$ value $=0.007)$ better prognosis for the early-stage (stages 1 and 2) patients when they are overexpressed (Fig. 6), while late-stage (stages 3 and 4) patients failed to show any significant association $(P$ value $=0.53)($ Additional file 2 : Figure S12G) .

\section{Discussion}

In this study, we determined the genome-wide methylation profile of well-differentiated OSCC and adjacent normal tissues. We identified several novel differentially methylated regions in oral cancer patients in India.

A total of 21,810 probes were identified to be differentially methylated in well-differentiated squamous cell carcinoma as compared to adjacent normal tissues. The analysis followed a stringent cut off of $|\Delta \beta| \geq 0.2$ and combined $P$ value $\leq 0.05$. DMPs were clustered in two distinct groups showing a clear difference in methylation pattern among disease and adjacent normal tissues of the same patients. Mis-clustering of the two normal samples were attributed to the hyperplastic to mild dysplastic features of these samples. Moreover, one of the patient was aged 90 years. The age of this patient was almost an outlier in the discovery set, and it may have modulated the epigenomic pattern of this patient. We found $25 \%$ of the DMPs were hypermethylated and the remaining $75 \%$ were hypomethylated. As observed in several cancers, we also found preferential enrichment of hypermethylated probes in the CpG-rich regions, while hypomethylated probes were primarily enriched at the open sea [28]. Interestingly, we have shown that the epigenetic drift at the CGIs, shores, and shelves were somewhat different for hyper- and hypomethylated. In case of hypermethylated promoters, no variation in the methylation pattern within the shore and shelves were observed. Only an abrupt and strong enrichment of hypermethylation in the CGI regions were observed. On the contrary, hypomethylated promoters showed hypomethylation getting spread towards the shore and shelves. This data suggests that two independent mechanisms of hypo- and hypermethylation are acting in OSCC development. It has recently been reported that the genome-wide hyper- and hypomethylation patterns are controlled by distinct sets of epigenetic enzymes, which is probably acting independent but 

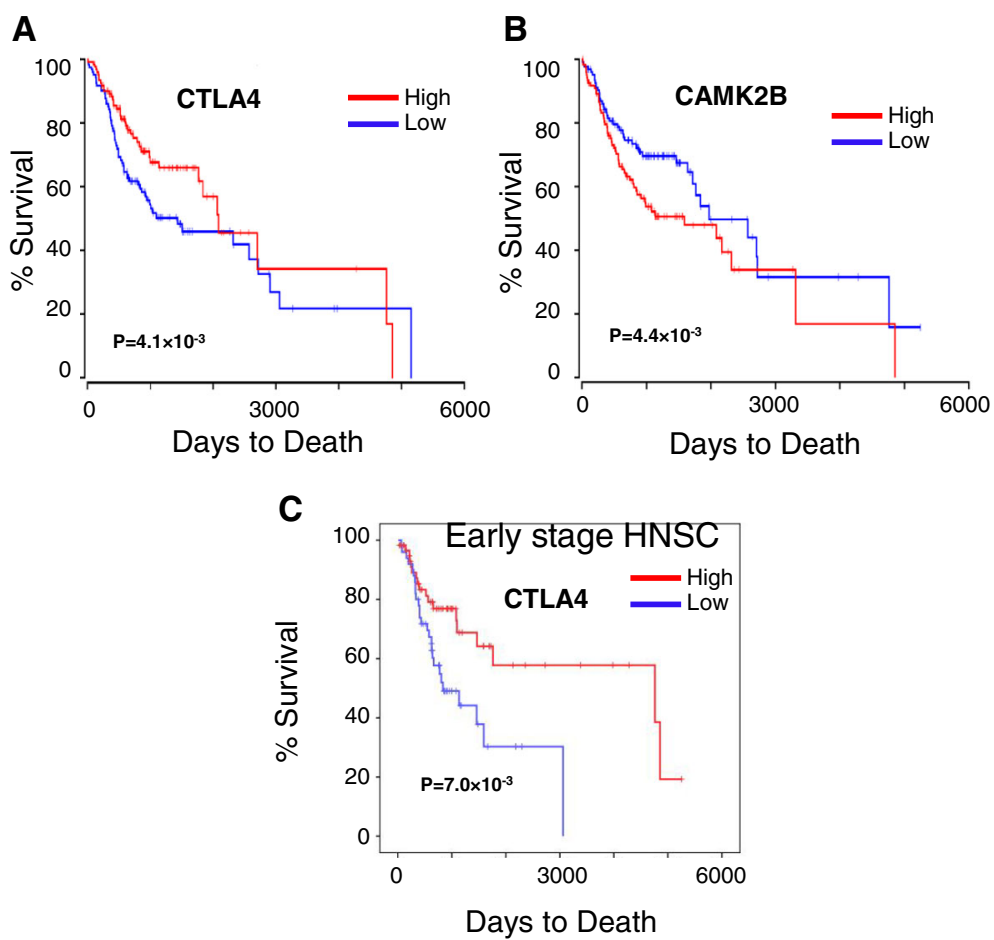

Fig. 6 Clinical significance of genes associated with uniquely hypomethylated probes. Kaplan-Meier plots of a CTLA4 showed higher gene expression (high, $N=124$ ) was significantly associated with better disease prognosis than low expression (low, $N=124$ ), while $\mathbf{b}$ lower expression of CAMK2B was associated with better prognosis. c Early-stage patients (stages 1 and 2) showed significantly better prognosis with higher expression of CTLA4. MantelCox log-rank $P$ values are presented with each survival analysis

simultaneously in two parts of the genome for hypoand hypermethylation $[29,30]$.

Aberrant promoter methylation leading to transcriptional deregulation of a gene are often found in cancers. In the present study, we focused on the DMPs that overlapped with the promoter regions. We have validated a panel of 14 differentially methylated promoters, identified from the genome-wide methylation data, in another cohort of 53 well-differentiated OSCC samples. Most of the promoter regions have shown methylation pattern consistent with the array data. We identified several novel candidate genes that were deregulated due to aberrant promoter methylation in OSCC. Differential methylation in promoters as well as altered expression of $L X N$, ZNF154, ZNF577, CTDSP1, RUNX1, CD28, and CD80 have not been reported previously in OSCC. $L X N$ mainly functions as a potential tumor suppressor and reduces the stem cells transformation into cancer stem cell. It has previously been shown to be inhibited by promoter hypermethylation in malignant melanoma, gastric cancer, and prostate cancer [31-34]. ZNF154 and ZNF577 downregulation has been reported to be associated with several cancers [35, 36]. Inhibition of CTDSP family members promotes the G1/S-phase transition and have been found to be downregulated in hepatocellular carcinoma [37]. Recently, epigenetic regulation of PTPN22 in the esophegal squamous cell carcinoma has been reported [38].We observed distinct hypomethylation of the PTPN22 promoter in OSCC, which also had inverse correlation with expression pattern of the gene.

Oral cancer is one of the most common malignancies in India [2]. Environmental exposure to genotoxic agents such as betel quid, gutkha, chewing tobacco, smoking, and alcohol have been identified as risk factors towards the development of oral cancer $[39,40]$. Although methanolic extract of Piper betel L. has been reported to have immunosuppressive effects [41], however, when consumed in combination with areca nut and slaked lime (betel quid), it can be harmful. Areca nut has been identified as an independent group I human carcinogen [42]. Areca nut chewed in different forms is predominant among the peoples of South and Southeast Asian countries [43]. Pan masala and gutkha, which have very high concentration of areca nut, have become very popular in India and Pakistan, especially among adolescents $[44,45]$. These genotoxic agents might be acting synergistically along with the epigenetic machinery towards oral cancer pathogenesis. Considering the varied exposure to these populations, we compared the methylation profile of Indian patients with TCGA HNSC methylation data. Hypermethylated probes identified in OSCC tissues of Indian patients are almost same with that of the TCGA 
samples. However, we determined a set of hypomethylated probes that are specific to the Indian patients. Promoter of some of the carcinogen-metabolizing genes like CYP8B1 and GSTA3 was found to be hypomethylated, specifically, in the tumor tissues of OSCC patients in India (Additional file 4: Table S4). Gene ontology analysis showed enrichment of immune genes for the hypomethylated promoter in both common and unique clusters. These data reflects the cell-type composition of the tumor microenvironment and, in particular, lymphocyte infiltration in these tumors. A closer look at these genes revealed that the hypomethylation occurred at promoters of genes involved in $\mathrm{T}$ lymphocytes regulation. Genes encoding cytotoxic T cell markers, like the $C D 8$ and $\mathrm{T}$ cell activation markers, like CD28, CD80, CD86, ZAP70, PI3 kinase or the PTPN22 tyrosine phosphatase involved in T cell receptor signaling, and CTLA4 involved in negatively regulating cytotoxic $\mathrm{T}$ cell signaling, are hypomethylated and overexpressed in the neoplastic environment. We considered whole tumor tissues for our DNA methylation analysis. These tissues are composed of mainly epithelial cells; however, cells from the surrounding stroma, including fibroblasts, extracellular matrix, and immune cells, are also present in the microenvironment [46]. Hypomethylation of immune genes in unique and common clusters are clear indication of infiltration of immune cells into tumors. Ingenuity pathway analysis with the unique differentially methylated promoters revealed enrichment of a distinct set of genes involved in immune response pathways. CTLA4 signaling in cytotoxic T lymphocytes is one of the most significant pathway enriched by these unique set of hypomethylated genes. These data indicated that the OSCC patients in India induce an anti-tumor $\mathrm{T}$ cell response, with mobilization of $\mathrm{T}$ lymphocytes in the tumor microenvironment. This is in accordance with the different oral habits present among the OSCC patients in India.

Our study has identified 162 uniquely hypomethylated probes that mapped to 134 genes, associated with OSCC patients in India. Survivability analysis showed that expression of 19 of these genes was significantly correlated with better disease prognosis. None of these genes have previously been reported in OSCC. Interestingly, nine (CCR10, SLAMF1, TNFRSF4, APOBR, CLNK, CTLA4, FCRL6, P2RY14, and ZAP70) out of these 17 genes are known to be involved in immune response pathways, and better disease prognosis was achieved with higher expression of these genes. Signaling-lymphocyticactivation-molecule-family1 (SLAMF1) is mainly involved in signal transduction for lymphocyte activation [47]. Lower expression of SLAMF1 was found to be associated with unfavorable prognosis in CLL [48]. Tumor necrosis factor receptor superfamily, member 4 (TNFRSF4) is a co-stimulatory molecule, and agonists of this molecule have been described to increase antitumor immunity through enhancing $\mathrm{T}$ cell response and suppressing $\mathrm{T}$ reg cells $[49,50]$. TLR9 on plasmacytoid dendritic cells are involved in secretion of type I interferons that are involved in anti-tumor immunity [51]. Interaction of chemokine receptor 10 (CCR10) with its ligand causes $\mathrm{T}$ cell homing and metastasis in melanoma; higher expression of CCR10 was correlated with lower survival of glioblastoma patients [52]. ZAP-70 (zetachain (TCR)-associated protein kinase), involved in $\mathrm{T}$ cell activation, was however reported to show poor prognosis in B-CLL with higher expression [53]. Most importantly, we have observed all these genes to be regulated by hypomethylated regions in promoter that are unique among OSCC patients in India. Survivability analysis showed significant prognostic implications of expression profile of CTLA4 gene involved in negative regulation of the immune system [54-56]. Higher expression of the early-stage patients was observed to be associated with better survival of the patients. However, this is contradictory to the reported functionality of these genes in immune suppression. Higher expression of these genes causing immunosuppression should have resulted in poor prognosis of the disease [57-60]. For example, CTLA4 is known to be expressed by $\mathrm{T}$ reg cells and activated $\mathrm{T}$ cells to prevent further $\mathrm{T}$ cell activation and thereby causing inhibition of the anti-tumor immune response [54]. Interestingly, we observed better survivability with higher CTLA4 expression, only for the early-stage (stages I and II) OSCC patients. A humanized anti-CTLA4 monoclonal antibody (ipilimumab) was approved by the Food and Drug Administration (FDA) for metastatic and advanced melanoma. Clinical trials and combination trials are going on for other advance stage cancers including prostate, bladder, and lung cancer. Better survivability for the early-stage OSCC patients suggests that CTLA4 might be overexpressed on the surface of early-stage tumor cells, as have been observed on cancer cell lines as well as in non-small cell lung carcinoma [61, 62]. Binding of CTLA4 with its ligand on APCs triggered apoptosis of tumor cells further inhibited tumor progression. However, better understanding of the tumor microenvironment can lead to elucidation of the actual role of CTLA4 in OSCC prognosis.

\section{Conclusions}

In summary, genome-wide DNA methylation profiling among OSCC patients in India thus revealed a set of differentially methylated regions, which were replicated in $60-90 \%$ patients in a separate cohort of OSCC patients. Comparison of the observed methylation pattern with TCGA HNSC methylation data revealed 94.6\% similarities, indicating their important role in cancer development. 
Interestingly, we also observed $5.3 \%$ probes that were uniquely differentially methylated in Indian patients, which might be attributed to different oral habits observed in Indian patients. Further studies correlating methylation pattern with different oral habits might give insights into their role in cancer development. Gene ontology and IPA showed enrichment of differentially methylated promoters in immune regulation pathways including those mediated by CTLA4 and IL9 signaling. Our study thus highlights the finding of a distinct set of differentially methylated regions among Indian OSCC patients as well as a strong immune component that is regulated by methylation.

\section{Methods}

\section{Patient selection and sample collection}

After clinical inspection, patients with provisional diagnosis of oral squamous cell carcinoma (OSCC) were recruited for the study with their written consent. Sixty-four patients were included in the study after confirmation of well-differentiated squamous cell carcinoma from histopathological reports. The study was approved by the Institutional Ethics Committee for Human Research of Indian Statistical Institute, Kolkata, India. Tissues from the area of the lesion and adjoining clinically uninvolved area were collected using incisional and 3-mm punch biopsy, respectively for all 64 patients. A portion of the tissue samples were collected in RNA Later (Invitrogen) and stored at $-80{ }^{\circ} \mathrm{C}$ until processing. Another portion was fixed in the formalin and used for histopathological evaluations.

Demographic information of the OSCC patients for both discovery and validation cohort are presented in Table 1 and Additional file 1: Table S1. Mean age of the patients of discovery set was $51.37(\mathrm{SD} \pm 14.33$ ) (range 40-90 years), while that of validation cohort was 53.35 (SD \pm 12.35$)$ (range $27-78$ years). The patient samples of discovery and validation cohort had no significant difference of age $(P$ value $=0.306)$, as calculated using the D'Agostino-Pearson omnibus normality test. There was no significant deviation in the distribution of males and females among OSCC patients $(P$ value $=0.529)$ in both cohorts. Nearly $82 \%$ cases from the both cohorts had oral habits.

\section{Illumina Infinium HumanMethylation450K bead chip and data analysis}

DNA was isolated from the lesion and adjacent uninvolved area using DNeasy Blood and Tissue Kit (Qiagen) following manufacturer's protocol. The purity and concentration of DNA was estimated using Nanodrop 2000 (ThermoScietific). Approximately, $500 \mathrm{ng}$ of genomic DNA from each sample was used for sodium bisulfite conversion using the EZ DNA methylation Gold Kit (Zymo Research, USA) following the manufacturer's standard protocol. Genome-wide DNA methylation was assessed using the Illumina Infinium HumanMethylation450 BeadChip (Illumina Inc, USA) according to manufacturer's instructions. Ten paired and one unpaired DNA samples were subjected to Infinium HumanMethylation $450 \mathrm{~K}$ bead chip analysis to interrogate 485,577 methylation sites per sample at singlenucleotide resolution. The array data (IDAT files) was analyzed using RnBeads package in $\mathrm{R}$ for deriving the methylation level [63]. The methylation status of all the probes was denoted as $\beta$ value, which is the ratio of the methylated probe intensity to the overall probe intensity (sum of methylated and unmethylated probe intensities plus constant $\alpha$, where $\alpha=100$ ). CpG sites having $|\Delta \beta|$ $\geq 0.20$ (in OSCC vs adjacent normal) and adjusted $P$ value $\leq 0.05$ was considered as differentially methylated site. A CpG was considered hypermethylated if $\Delta \beta \geq 0.20$ or hypomethylated if $\Delta \beta \leq-0.20$. Average $\beta$ value of promoters and $\mathrm{CpG}$ islands were compared between disease and normal. Promoters and CGIs with $|\Delta \beta| \geq 0.20$ and adjusted $P$ value $\leq 0.05$ were considered for further analysis. Heatmaps were generated using gplots package in $R$. The data has been submitted to the Gene Expression Omnibus (GEO) with accession number GSE87053.

\section{HPV determination by PCR}

Presence of integrated HPV sequences was detected from DNA isolated from diseased tissue by PCR with primers specific for the conserved L1 region of viral genome using the method as described previously [64].

\section{Comparison with TCGA methylation data}

The methylation data of our study were compared with a publically available, open access methylation dataset of HNSC from The Cancer Genome Atlas (TCGA) (https://tcga-data.nci.nih.gov/docs/publications/tcga/?). In order to ensure equivalent comparisons, TCGA samples with malignancies at the larynx, alveolar ridge, oropharynx, hypopharynx, and tonsil were not included in this study (Additional file 3: Table S2). RnBeads package was used for analysis of TCGA samples. The differentially methylated probes, promoters and $\mathrm{CpG}$ islands observed in our samples were compared with the TCGA samples.

\section{Identification of common and unique probes}

The total hypomethylated probes were categorized into two categories viz common and unique. All stages (S1-S4) of TCGA data were compared with OSCC disease samples. The unique probes were significantly different (adjusted $P$ value $\leq 0.05$ ) from each stages of TCGA samples. Those DMPs that were similar (i.e., not significantly different) to any stages of the TCGA samples were considered as common hypo- or hypermethylated probes. 


\section{Bisulfite sequencing PCR and quantitative real-time PCR for methylation analysis}

The bisulfite sequencing PCR (BSP) were carried out for 14 promoters by bisulfite conversion-specific primers (Additional file 5: Table S5) designed using MethPrimer [65]. The BSP products were analyzed on 1\% agarose gel. A part of BSP products were then used for the quantitative real-time methylation-specific PCR (qMSP). The qMSP reactions were carried out using methylationspecific primers (Additional file 5: Table S5) with FastStart Universal SYBR Green Master Mix (Rox) (Roche, Switzerland) in a 7900HT Fast Real-Time PCR System Instrument (ABI, USA).

\section{BSP cloning and sequencing}

The BSP products were then selected for cloning and sequencing. Another part of the BSP products was purified with the MiniElute Gel extraction Kit (Qiagen Inc., USA). About $165 \mathrm{ng}$ of the purified BSP product was ligated in the TA vector (PTZ57R/T) using T4 DNA Ligase (Takara Bio Inc., Japan). The ligated product were then transformed into E.coliDH5 $\alpha$ cells and plated on LA-Ampicillin plates. The probable positive clones were verified by colony PCR using universal M13 forward and reverse primer and under standard conditions. The positive clones were then sequenced in 3100 Genetic Analyzer (ABI, USA). The status of methylation of each clone were analyzed from the chromatogram thus obtained, and the percentage methylation was calculated.

\section{Gene expression study}

Twenty paired tissue samples were selected for expression analysis of the identified genes with differentially methylated promoters. Biopsy samples stored in RNA Later Solution (Invitrogen, USA) at $-80{ }^{\circ} \mathrm{C}$ were used. Tissue samples were snap frozen in liquid nitrogen and grinded using mortar and pestle. Total RNA was extracted using High Pure RNA Tissue Kit (Roche). Quality of the eluted RNA was checked in Nanodrop spectrophotometer. Samples with low RNA yield or impure RNA was not considered for further study. One microgram of total RNA was used for complementary DNA (cDNA) synthesis using RevertAid First Strand cDNA Synthesis Kit (Thermo Scientific). The product was subsequently diluted, and around $10 \mathrm{ng}$ was finally used for each reaction. Transcripts were quantified using specific gene expression primers (Additional file 6: Table S6) in 7900HT Fast Real-Time PCR system (Applied Biosystems) using FastStart Universal SYBR Green Master (Rox) (Roche). All values were normalized to the expression of the housekeeping gene ribonuclease P (RPP30).

\section{Survival analysis}

To determine the clinical significance of the unique hypomethylated genes, we analyzed methylation and expression values of all 134 genes with the clinical follow up data available at TCGA. Survival analysis for the gene expression data were performed using OncoLnc [66]. Top and bottom 25 percentile of expression values were considered as high and low groups, respectively. Survival analyses of the unique DMPs were done using the Kaplan-Meier survival analysis in SPSS. Mantel-Cox $\log$-rank $P$ value $\leq 0.05$ was considered as significant. The patients were sorted based on their $\beta$ values for each unique DMP. Low and high groups are generated from the top and bottom 25 percentile patients.

\section{Additional files}

Additional file 1: Table S1. Clinical and demographic charecteristics of the discovery and validation cohort samples. (XLSX 14 kb)

Additional file 2: Figure S1. Histopathogical images of mis-clustered samples. Figure S2. Genomic distribution of DMPs. Figure S3. Hierarchical clustering of average methylation. Figure S4. Validation of HumanMethylation450K bead chip data. Figure S5. Expression profile of genes with hypermethylated promoters. Figure S6. Expression profile of genes with hypomethylated promoters. Figure S7. Comparison of methylation pattern in adjacent normal, OSCC, and different stages of TCGA sample. Figure S8. Comparison of common hypomethylated probes. Figure S9. Comparison of unique hypomethylated probes. Figure S10. Gene ontology analysis of DMPs. Figure $\mathbf{S 1 1}$. Clinical significance of immune genes associated with uniquely hypomethylated probes. Figure S12. Clinical significance of non-immune genes associated with uniquely hypomethylated probes. (PDF $2377 \mathrm{~kb}$ )

Additional file 3: Table S2. Clinical and demographic charecteristics of the TCGA samples included in this study. Table S3. Hazard ratio estimated in cox model based on death due to oral cancer by age, stage and node involvement. (XLSX $54 \mathrm{~kb}$ )

Additional file 4: Table S4. Spreadsheet showing list of all unique differentially methylated probes. (XLSX 23 kb)

Additional file 5: Table S5. Primer sequences used for BSP and qMSP studies. (DOCX $16 \mathrm{~kb}$ )

Additional file 6: Table S6. Primer sequences used for gene expression study. (DOCX $13 \mathrm{~kb}$ )

\section{Acknowledgements}

BB and AC were supported by the CSIR fellowship. JC is supported by the DST-INSPIRE fellowship. Authors would like to acknowledge all the patients who participated in the study.

\section{Funding}

This study is funded by the Council of Scientific and Industrial Research (Grant no 27(0306)/14//EMR-II) and Indian Statistical Institute.

\section{Availability of data and materials}

Illumina InfinumHuman 450K bead chip data has been submitted to Gene Expression Omnibus (GEO) with accession number GSE87053 (https://www.ncbi.nlm.nih.gov/geo/query/acc.cgi?acc=GSE87053).

\section{Authors' contributions}

$B B, A C, A K$, and $R C$ conducted the experiments. JC and RC conducted the bioinformatics analysis. JRKB, DDC, and JGR recruited the patients and conducted the histopathological studies. RC conceived the study. BB, JC, AC, $\mathrm{KC}$, and $\mathrm{RC}$ wrote the manuscript. All authors read and approved the final manuscript. 


\section{Competing interests}

The authors declare that they have no competing interests.

\section{Consent for publication}

Not applicable.

\section{Ethics approval and consent to participate}

This study is conducted after obtaining the ethical approval from the "Review Committee for Protection of Research Risks to Humans" of Indian Statistical Institute. Experimental methods comply with the guidelines of the Declaration of Helsinki. Patients were recruited in the study after obtaining their written consent to participate.

\section{Author details}

${ }^{1}$ Human Genetics Unit, Indian Statistical Institute, 203 B. T. Road, Kolkata 700108, India. ${ }^{2}$ Molecular Genetics Division, CSIR-Indian Institute of Chemical biology, 4 Raja S C Mullick Road, Kolkata 700 032, India. ${ }^{3}$ Dr. R Ahmed Dental College \& Hospital, 114, A J C Bose Road, Kolkata, India.

\section{Received: 6 October 2016 Accepted: 19 January 2017} Published online: 03 February 2017

\section{References}

1. Torre LA, Bray F, Siegel RL, Ferlay J, Lortet-Tieulent J, Jemal A. Global cancer statistics, 2012. CA Cancer J Clin. 2015;65:87-108.

2. Llewellyn CD, Johnson NW, Warnakulasuriya KA. Risk factors for squamous cell carcinoma of the oral cavity in young people-a comprehensive literature review. Oral Oncol. 2001;37:401-18.

3. Byakodi R, Byakodi S, Hiremath S, Byakodi J, Adaki S, Marathe K, Mahind P. Oral cancer in India: an epidemiologic and clinical review. J Community Health. 2012;37:316-9.

4. Silverman Jr S, Gorsky M, Lozada F. Oral leukoplakia and malignant transformation. A follow-up study of 257 patients. Cancer. 1984;53:563-8.

5. Warnakulasuriya S, Johnson NW, van der Waal I. Nomenclature and classification of potentially malignant disorders of the oral mucosa. J Oral Pathol Med. 2007:36:575-80.

6. Feinberg AP, Vogelstein B. Hypomethylation distinguishes genes of some human cancers from their normal counterparts. Nature. 1983;301:89-92.

7. Baylin SB, Jones PA. A decade of exploring the cancer epigenome-biological and translational implications. Nat Rev Cancer. 2011; 11:726-34.

8. Esteller M. Cancer epigenetics for the 21st century: what's next? Genes Cancer. 2011;2:604-6.

9. Rodriguez-Paredes M, Esteller M. Cancer epigenetics reaches mainstream oncology. Nat Med. 2011;17:330-9.

10. Chatterjee R, Vinson C. CpG methylation recruits sequence specific transcription factors essential for tissue specific gene expression. Biochim Biophys Acta. 1819;2012:763-70.

11. Laird PW. The power and the promise of DNA methylation markers. Nat Rev Cancer. 2003;3:253-66.

12. Kato K, Hara A, Kuno T, Mori H, Yamashita T, Toida M, Shibata T. Aberrant promoter hypermethylation of p16 and MGMT genes in oral squamous cell carcinomas and the surrounding normal mucosa. J Cancer Res Clin Oncol. 2006;132:735-43.

13. Towle R, Truong D, Hogg K, Robinson WP, Poh CF, Garnis C. Global analysis of DNA methylation changes during progression of oral cancer. Oral Oncol. 2013;49:1033-42.

14. Scully C, Field JK, Tanzawa H. Genetic aberrations in oral or head and neck squamous cell carcinoma (SCCHN): 1. Carcinogen metabolism, DNA repair and cell cycle control. Oral Oncol. 2000;36:256-63.

15. Gao S, Nielsen BS, Krogdahl A, Sorensen JA, Tagesen J, Dabelsteen S, Dabelsteen E, Andreasen PA. Epigenetic alterations of the SERPINE1 gene in oral squamous cell carcinomas and normal oral mucosa. Genes Chromosomes Cancer. 2010;49:526-38.

16. Demokan S, Dalay N. Role of DNA methylation in head and neck cancer. Clin Epigenetics. 2011;2:123-50.

17. Ralhan R, Chakravarti N, Kaur J, Sharma C, Kumar A, Mathur M, Bahadur S, Shukla NK, Deo SV. Clinical significance of altered expression of retinoid receptors in oral precancerous and cancerous lesions: relationship with cell cycle regulators. Int J Cancer. 2006;118:1077-89.
18. Radhakrishnan R, Kabekkodu S, Satyamoorthy K. DNA hypermethylation as an epigenetic mark for oral cancer diagnosis. J Oral Pathol Med. 2011;40:665-76.

19. Gonzalez-Ramirez I, Ramirez-Amador V, Irigoyen-Camacho ME, SanchezPerez Y, Anaya-Saavedra G, Granados-Garcia M, Garcia-Vazquez F, GarciaCuellar CM. hMLH1 promoter methylation is an early event in oral cancer. Oral Oncol. 2011:47:22-6.

20. Shaw RJ, Liloglou T, Rogers SN, Brown JS, Vaughan ED, Lowe D, Field JK, Risk JM. Promoter methylation of P16, RARbeta, E-cadherin, cyclin A1 and cytoglobin in oral cancer: quantitative evaluation using pyrosequencing. $\mathrm{Br}$ J Cancer. 2006;94:561-8.

21. Li Y, Li B, Xu B, Han B, Xia H, Chen QM, Li LJ. Expression of p53, p21(CIP1/ WAF1) and elF4E in the adjacent tissues of oral squamous cell carcinoma: establishing the molecular boundary and a cancer progression model. Int J Oral Sci. 2015;7:161-8.

22. Li YF, Hsiao YH, Lai YH, Chen YC, Chen YJ, Chou JL, Chan MW, Lin YH, Tsou YA, Tsai MH, Tai CK. DNA methylation profiles and biomarkers of oral squamous cell carcinoma. Epigenetics. 2015;10:229-36.

23. Kulkarni V, Saranath D. Concurrent hypermethylation of multiple regulatory genes in chewing tobacco associated oral squamous cell carcinomas and adjacent normal tissues. Oral Oncol. 2004;40:145-53.

24. Viswanathan M, Tsuchida N, Shanmugam G. Promoter hypermethylation profile of tumor-associated genes p16, p15, hMLH1, MGMT and E-cadherin in oral squamous cell carcinoma. Int J Cancer. 2003;105:41-6.

25. Kaur J, Demokan S, Tripathi SC, Macha MA, Begum S, Califano JA, Ralhan R. Promoter hypermethylation in Indian primary oral squamous cell carcinoma. Int J Cancer. 2010;127:2367-73.

26. Talukdar FR, Ghosh SK, Laskar RS, Mondal R. Epigenetic, genetic and environmental interactions in esophageal squamous cell carcinoma from northeast India. PLoS One. 2013;8:e60996.

27. Bibikova M, Le J, Barnes B, Saedinia-Melnyk S, Zhou L, Shen R, Gunderson $\mathrm{KL}$. Genome-wide DNA methylation profiling using Infinium (R) assay. Epigenomics. 2009;1:177-200.

28. Shen J, Wang S, Zhang YJ, Wu HC, Kibriya MG, Jasmine F, Ahsan H, Wu DP, Siegel AB, Remotti $H$, Santella RM. Exploring genome-wide DNA methylation profiles altered in hepatocellular carcinoma using Infinium HumanMethylation 450 BeadChips. Epigenetics. 2013:8:34-43.

29. Frigola J, Sole X, Paz MF, Moreno V, Esteller M, Capella G, Peinado MA. Differential DNA hypermethylation and hypomethylation signatures in colorectal cancer. Hum Mol Genet. 2005;14:319-26.

30. Yang $Z$, Jones $A$, Widschwendter $M$, Teschendorff AE. An integrative pancancer-wide analysis of epigenetic enzymes reveals universal patterns of epigenomic deregulation in cancer. Genome Biol. 2015;16:140.

31. Oldridge EE, Walker HF, Stower MJ, Simms MS, Mann VM, Collins AT, Pellacani D, Maitland NJ. Retinoic acid represses invasion and stem cell phenotype by induction of the metastasis suppressors RARRES1 and LXN. Oncogenesis. 2013;2:e45.

32. Li Y, Basang Z, Ding H, Lu Z, Ning T, Wei H, Cai H, Ke Y. Latexin expression is downregulated in human gastric carcinomas and exhibits tumor suppressor potential. BMC Cancer. 2011;11:121.

33. Muthusamy V, Duraisamy S, Bradbury CM, Hobbs C, Curley DP, Nelson B, Bosenberg M. Epigenetic silencing of novel tumor suppressors in malignant melanoma. Cancer Res. 2006;66:11187-93.

34. Kloth M, Goering W, Ribarska T, Arsov C, Sorensen KD, Schulz WA. The SNP rs6441224 influences transcriptional activity and prognostically relevant hypermethylation of RARRES1 in prostate cancer. Int J Cancer. 2012;131: E897-904.

35. Sanchez-Vega F, Gotea V, Petrykowska HM, Margolin G, Krivak TC, DeLoia JA, Bell DW, Elnitski L. Recurrent patterns of DNA methylation in the ZNF154, CASP8, and VHL promoters across a wide spectrum of human solid epithelial tumors and cancer cell lines. Epigenetics. 2013;8: 1355-72.

36. Barrio S, Gallardo M, Albizua E, Jimenez A, Rapado I, Ayala R, Gilsanz F, Martin-Subero Jl, Martinez-Lopez J. Epigenomic profiling in polycythaemia vera and essential thrombocythaemia shows low levels of aberrant DNA methylation. J Clin Pathol. 2011;64:1010-3.

37. Zhu Y, Lu Y, Zhang Q, Liu JJ, Li TJ, Yang JR, Zeng C, Zhuang SM. MicroRNA$26 \mathrm{a} / \mathrm{b}$ and their host genes cooperate to inhibit the G1/S transition by activating the pRb protein. Nucleic Acids Res. 2012:40:4615-25.

38. Jiaying D, Junhua Z, Chunyu W, Qing W, Daizhan Z, Kuaile Z. Methylation and expression of PTPN22 in esophageal squamous cell carcinoma. Oncotarget. 2016; 7:64043-52.. 
39. Blot WJ, McLaughlin JK, Winn DM, Austin DF, Greenberg RS, Preston-Martin S, Bernstein L, Schoenberg JB, Stemhagen A, Fraumeni Jr JF. Smoking and drinking in relation to oral and pharyngeal cancer. Cancer Res. 1988;48: 3282-7.

40. Nair U, Bartsch H, Nair J. Alert for an epidemic of oral cancer due to use of the betel quid substitutes gutkha and pan masala: a review of agents and causative mechanisms. Mutagenesis. 2004;19:251-62.

41. Kanjwani DG, Marathe TP, Chiplunkar SV, Sathaye SS. Evaluation of immunomodulatory activity of methanolic extract of Piper betel. Scand J Immunol. 2008;67:589-93.

42. International agency for research on cancer WHO. larc monographs on the evaluation of the carcinogenic risk of chemicals to humans. International agency for research on cancer, World Health Organization. Vol. 37. Lyon: IARC; 1985.

43. Auluck A, Hislop G, Poh C, Zhang L, Rosin MP. Areca nut and betel quid chewing among South Asian immigrants to Western countries and its implications for oral cancer screening. Rural Remote Health. 2009;9:1118.

44. Gupta PC, Warnakulasuriya S. Global epidemiology of areca nut usage. Addict Biol. 2002;7:77-83.

45. Gupta B, Johnson NW. Systematic review and meta-analysis of association of smokeless tobacco and of betel quid without tobacco with incidence of oral cancer in South Asia and the Pacific. PLoS ONE. 2014;9:e113385.

46. Li H, Fan $\mathrm{X}$, Houghton J. Tumor microenvironment: the role of the tumor stroma in cancer. J Cell Biochem. 2007;101:805-15.

47. Engel P, Eck MJ, Terhorst C. The SAP and SLAM families in immune responses and X-linked lymphoproliferative disease. Nat Rev Immunol. 2003; 3:813-21.

48. Bologna C, Buonincontri R, Serra S, Vaisitti T, Audrito V, Brusa D, Pagnani A, Coscia M, D'Arena G, Mereu E, et al. SLAMF1 regulation of chemotaxis and autophagy determines CLL patient response. J Clin Invest. 2016;126:181-94.

49. Linch SN, Kasiewicz MJ, McNamara MJ, Hilgart-Martiszus IF, Farhad M, Redmond WL. Combination OX40 agonism/CTLA-4 blockade with HER2 vaccination reverses T-cell anergy and promotes survival in tumor-bearing mice. Proc Natl Acad Sci U S A. 2016;113:E319-27.

50. Redmond WL, Linch SN, Kasiewicz MJ. Combined targeting of costimulatory (OX40) and coinhibitory (CTLA-4) pathways elicits potent effector T cells capable of driving robust antitumor immunity. Cancer Immunol Res. 2014;2: 142-53.

51. Kim TW, Hong S, Lin Y, Murat E, Joo H, Kim T, Pascual V, Liu YJ. Transcriptional repression of IFN regulatory factor 7 by MYC is critical for type I IFN production in human plasmacytoid dendritic cells. J Immunol. 2016.

52. Chen L, Liu X, Zhang HY, Du W, Qin Z, Yao Y, Mao Y, Zhou L. Upregulation of chemokine receptor CCR10 is essential for glioma proliferation, invasion and patient survival. Oncotarget. 2014;5:6576-83.

53. Hus I, Podhorecka M, Bojarska-Junak A, Rolinski J, Schmitt M, Sieklucka M, Wasik-Szczepanek E, Dmoszynska A. The clinical significance of ZA70 and CD38 expression in B-cell chronic lymphocytic leukaemia. Ann Oncol. 2006; 17:683-90.

54. Krummel MF, Allison JP. CD28 and CTLA-4 have opposing effects on the response of T cells to stimulation. J Exp Med. 1995;182:459-65.

55. Wu Y, Borde M, Heissmeyer V, Feuerer M, Lapan AD, Stroud JC, Bates DL, Guo L, Han A, Ziegler SF, et al. FOXP3 controls regulatory T cell function through cooperation with NFAT. Cell. 2006;126:375-87.

56. Zou W, Chen L. Inhibitory B7-family molecules in the tumour microenvironment. Nat Rev Immunol. 2008;8:467-77.

57. Lipson EJ, Drake CG. Ipilimumab: an anti-CTLA-4 antibody for metastatic melanoma. Clin Cancer Res. 2011;17:6958-62.

58. Kvistborg P, Philips D, Kelderman S, Hageman L, Ottensmeier C, JosephPietras D, Welters MJ, van der Burg S, Kapiteijn E, Michielin O, et al. AntiCTLA-4 therapy broadens the melanoma-reactive CD8+ T cell response. Sci Transl Med. 2014;6:254ra128.

59. Kwek SS, Dao V, Roy R, Hou Y, Alajajian D, Simko JP, Small EJ, Fong L. Diversity of antigen-specific responses induced in vivo with CTLA-4 blockade in prostate cancer patients. J Immunol. 2012;189:3759-66.

60. Callahan MK, Wolchok JD. At the bedside: CTLA-4- and PD-1-blocking antibodies in cancer immunotherapy. J Leukoc Biol. 2013;94:41-53.

61. Contardi E, Palmisano GL, Tazzari PL, Martelli AM, Fala F, Fabbi M, Kato T, Lucarelli E, Donati D, Polito L, et al. CTLA-4 is constitutively expressed on tumor cells and can trigger apoptosis upon ligand interaction. Int J Cancer. 2005;117:538-50.
62. Salvi S, Fontana V, Boccardo S, Merlo DF, Margallo E, Laurent S, Morabito A, Rijavec E, Dal Bello MG, Mora M, et al. Evaluation of CTLA-4 expression and relevance as a novel prognostic factor in patients with non-small cell lung cancer. Cancer Immunol Immunother. 2012;61:1463-72.

63. Assenov Y, Muller F, Lutsik P, Walter J, Lengauer T, Bock C. Comprehensive analysis of DNA methylation data with RnBeads. Nat Methods. 2014;11: 1138-40.

64. Matsha T, Erasmus R, Kafuko AB, Mugwanya D, Stepien A, Parker MI, Group CMOCR. Human papillomavirus associated with oesophageal cancer. J Clin Pathol. 2002;55:587-90.

65. Li LC, Dahiya R. MethPrimer: designing primers for methylation PCRs. Bioinformatics. 2002;18:1427-31.

66. Anaya J. OncoLnc: linking TCGA survival data to mRNAs, miRNAs, and IncRNAs. PeerJ Comput Sci. 2016;2:e67.

\section{Submit your next manuscript to BioMed Central and we will help you at every step:}

- We accept pre-submission inquiries

- Our selector tool helps you to find the most relevant journal

- We provide round the clock customer support

- Convenient online submission

- Thorough peer review

- Inclusion in PubMed and all major indexing services

- Maximum visibility for your research

Submit your manuscript at www.biomedcentral.com/submit
Biomed Central 